\title{
Short Branching in Poly(vinyl alcohol). I. Syntheses of the Model Polymers
}

\author{
Yotaro Morishima, Yoshio Irie, Hiroyuki Iimuro, and Shun-ichi Nozakura \\ Department of Polymer Science, Faculty of Science, Osaka University, Toyonaka 560, Japan.
}

(Received December 16, 1974)

\begin{abstract}
Syntheses of model polymers of poly(vinyl alcohol)(PVA) having short branches are described. The copolymerization of vinyl acetate(VAc) and 2,4-diacetoxy-1butene(DAB) followed by subsequent hydrolysis gave a model PVA with short branches of one monomer unit in length. In the same manner, a model PVA having short branches of two monomer units in length was obtained from the copolymer of VAc and 1,3,5-triacetoxy-5-hexene(TAH). The monomer reactivity ratios are $r_{\nabla A C}=1.63 \pm 0.07$ and $r_{\mathrm{DAB}}=$ $0.52 \pm 0.13$ for the VAc-DAB copolymerization at $0^{\circ} \mathrm{C}$, and $r_{\mathrm{VAc}}=1.49 \pm 0.03$ and $r_{\mathrm{TAH}}=$ $0.67 \pm 0.14$ for VAc-TAH at $60^{\circ} \mathrm{C}$.

KEY WORDS Poly(vinyl alcohol) / Short Branching / Copolymerization / 2,4-Diacetoxy-1-Butene / 1,3,5-Triacetoxy-5-Hexene /
\end{abstract}

Among the structural characteristics such as molecular weight and its distribution, head-to-tail structures, terminal groups, stereoregularity, and branching of poly(vinyl alcohol)(PVA), many points still remain unsolved and ambiguous with reference to the problem of branching. The branches in PVA may be of two types, i.e., long branches of an average size comparable with that of the main chain, and short branches of only a few monomeric units in length. The formation of the long branches in PVA was investigated kinetically by the present authors ${ }^{1,2}$ and its presence was established experimentally. With regard to short branching however, no experimental techniques to prove its existence in PVA are known. There is no doubt that the short branches in PVA might affect its properties and, when some properties of PVA cannot be accounted for by the known structural factors as mentioned above, short branches have often been discussed as a possible factor. ${ }^{3,4}$

This work was undertaken to develop methods of measuring the amount of short chain branching in PVA and to clarify its effects on the polymer properties. The first approach is to synthesize a model PVA having a known amount of branches of known length.

The back-biting mechanism was proposed by Roedel $^{5}$ to explain the formation of short branches in polyethylene, being due to an intramolecular hydrogen-transfer reaction occurring via the transient 6-membered ring formation. This mechanism could be specific in favor of short branches of the butyl type. The double backbiting mechanism was also proposed ${ }^{6}$ in which 1,5 back-biting is followed by addition of one monomer and by subsequent 1,5 back-bitting. This route would lead to polyethylene with short branches of the ethyl type.

It is assumed by analogy with the ethylene polymerization that the probable short branching structures in PVA are one or two monomer units in length. In this paper, the syntheses of the following model polymers are described.<smiles>CCC(O)CC(C)(O)CCO</smiles>

PVA (I)<smiles>CCC(O)CC(C)(O)CC(O)CCO</smiles>

PVA (II) 
Models PVA(I) and PVA(II) were prepared by hydrolysis of the copolymer of vinyl acetate and 2,4diacetoxy-1-butene(DAB) and that of vinyl acetate and 1,3,5-triacetoxy-5-hexene(TAH), respectively. Monomers DAB and TAH are new compounds.

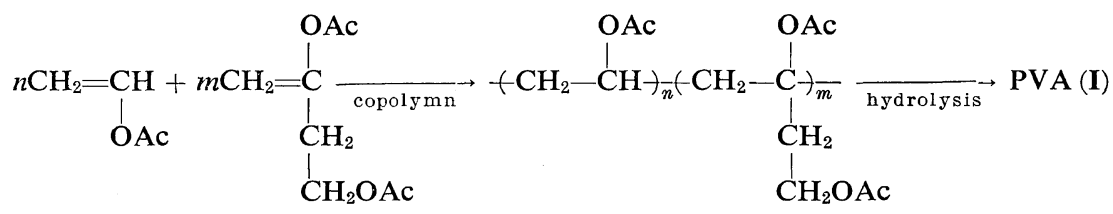

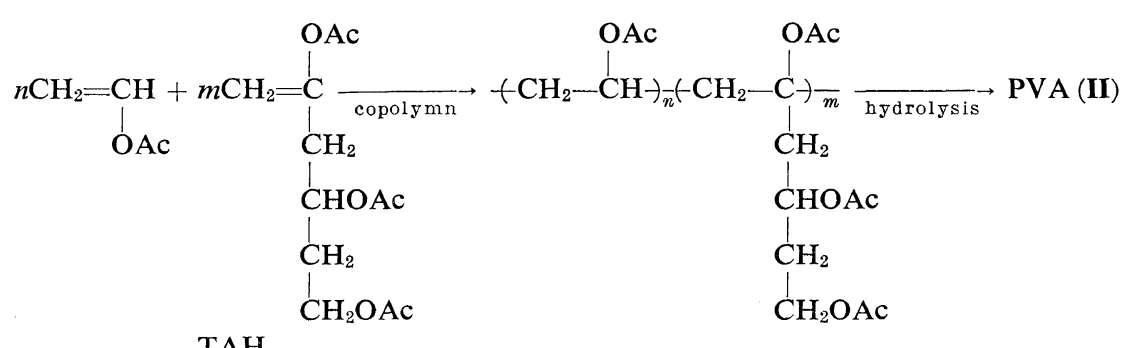

\section{RESULTS AND DISCUSSION}

Synthesis of 2,4-Diacetoxy-1-Butene

Monomer DAB was prepared according to the following series of reactions.

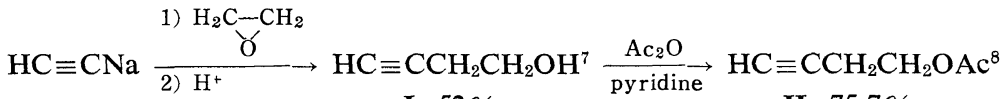

$$
\begin{aligned}
& \text { I, } 52 \% \quad \text { II, } 75.7 \% \\
& \underset{\mathrm{HgO}+\mathrm{BF}_{3} \mathrm{OEt}_{2}}{\rightarrow} \underset{\text { OAc }}{\stackrel{\mathrm{AcOH}}{\mathrm{H}}} \stackrel{\mathrm{H}_{2} \mathrm{C}=}{\mathrm{CCH}_{2} \mathrm{CH}_{2} \mathrm{OAc}}
\end{aligned}
$$

DAB, $28.8 \%$

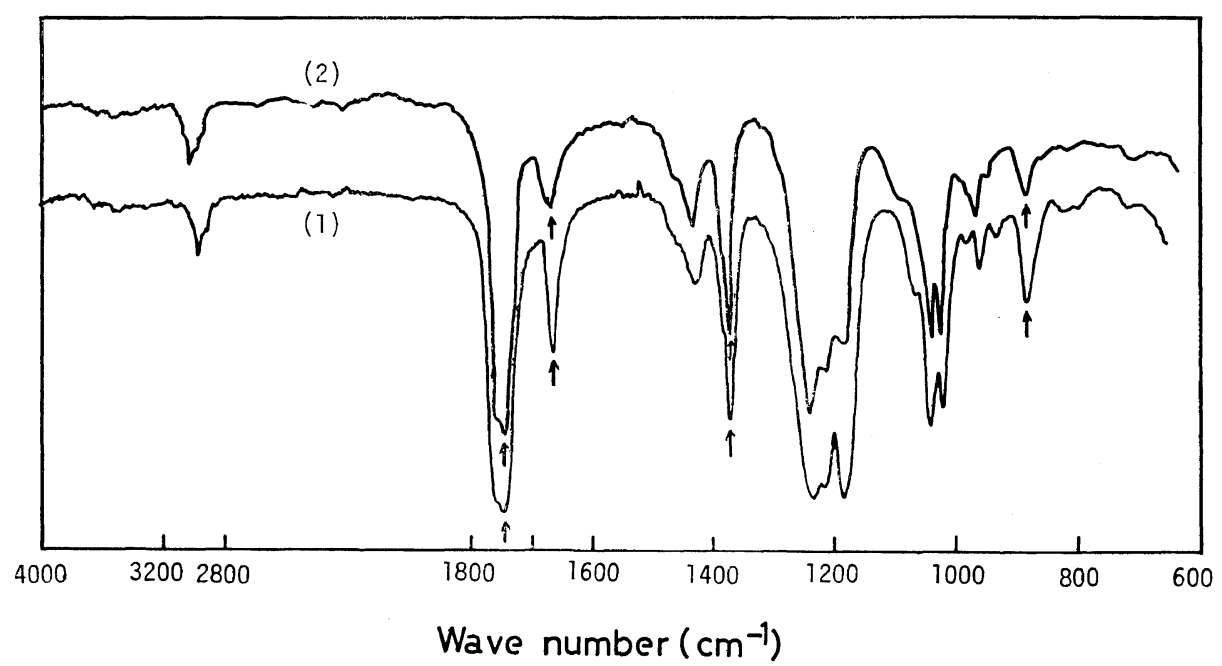

Figure 1. IR spectra of 2,4-diacetoxy-1-butene(DAB)(1) and 1,3,5-triacetoxy-5-hexene(TAH)(2). 
Short Branching in Poly(vinyl alcohol). I.

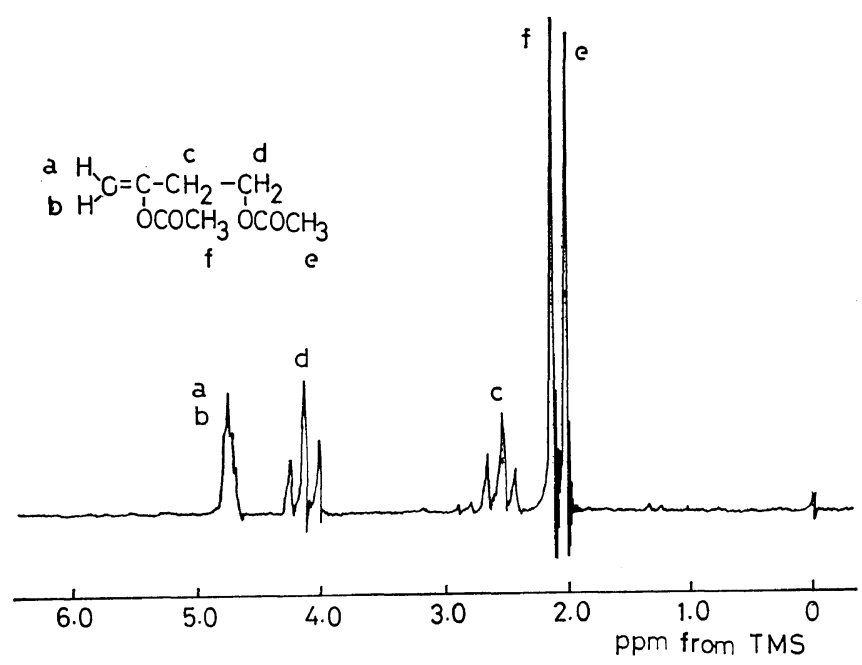

Figure 2. NMR spectrum of 2,4-diacetoxy-1-butene(DAB).

Figure 1 shows an IR spectrum of DAB. The characteristic absorption bands at 1745, 1665, 1373 , and $885 \mathrm{~cm}^{-1}$ were assigned to $\nu \mathrm{C}=\mathrm{O}$ (ester), $\nu \mathrm{C}=\mathrm{C}($ vinyl $), \delta_{\mathrm{s}} \mathrm{CH}_{3}\left(\right.$ acetyl), and $\delta \mathrm{CH}\left(\mathrm{CH}_{2}\right)$, respectively. In Figure 2 is shown an NMR spectrum of DAB together with the assignments of the resonance peaks.

In the last step of the synthesis (addition of acetic acid to 4-acetoxy-1-butyne(II)), 1-acetoxy-3butanone(III) was formed in considerable quantity as a by-product. III was isolated as a lower boiling distillate in the fractional distillation of the reaction mixture. According to the suggestion of Hennion and Nieuwland ${ }^{9}$ one of the possible route for the formation of III might be as follows

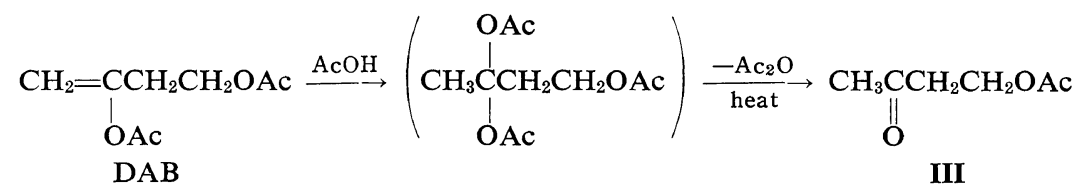

This side reaction could be responsible for the low yield of DAB.

Synthesis of 1,3,5-Triacetoxy-5-Hexene $(T A H)$

Four kinds of approach were attempted for the preparation of 1,3-diacetoxy-5-hexyne(V) which is the precurser of TAH.

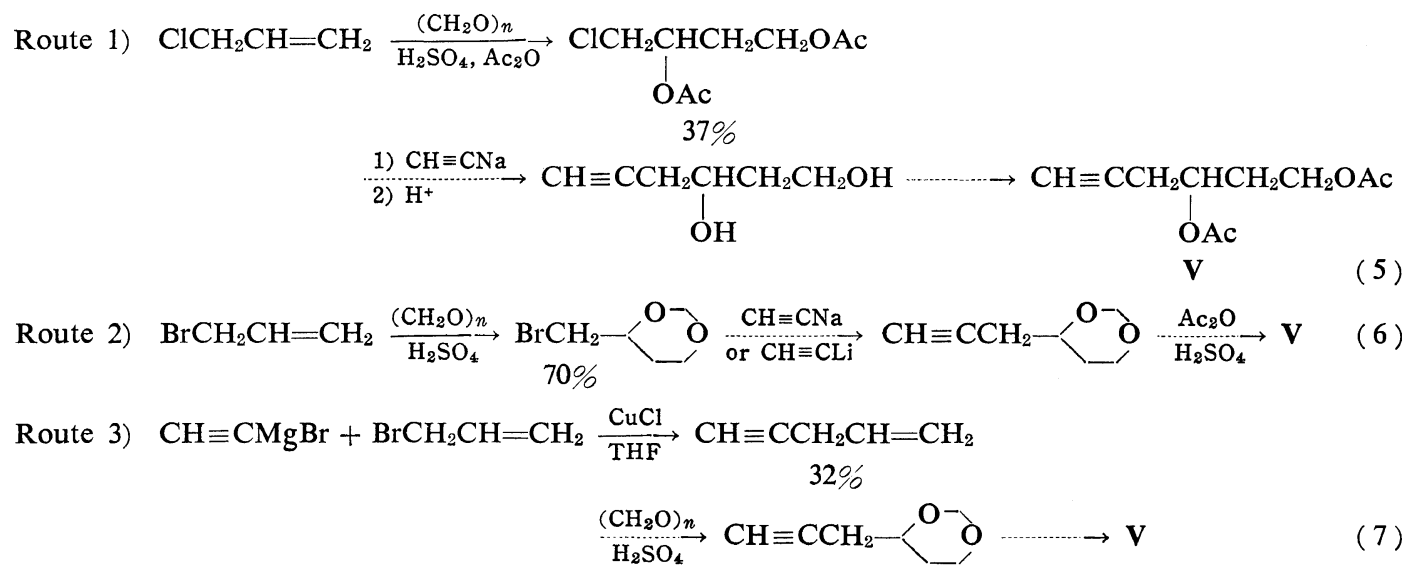


Route 4) $\mathrm{CH}_{2}=\mathrm{CHCHO} \frac{\mathrm{AcOH}}{\text { Amberlite, } \mathrm{IR} 400} \underset{\mathrm{AcOCH}}{\longrightarrow} \mathrm{CH}_{2} \mathrm{CHO}^{10} \frac{\text { 1) } \mathrm{CH} \equiv \mathrm{CCH}_{2} \mathrm{Br}+\mathrm{Zn}, \mathrm{THF}}{2) \mathrm{Ac}_{2} \mathrm{O}} \rightarrow$

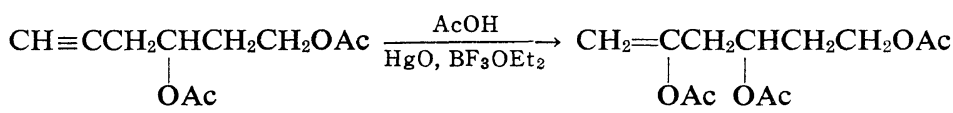

$$
\begin{aligned}
& \text { TAH, } 18.1 \%
\end{aligned}
$$

In route 1 , the first step is Prins reaction. ${ }^{11,12}$ The reaction of 2,4-diacetoxybutyl chloride and sodium acetylide gave three main fractions in the fractional distillation all of which are composed of complicated mixtures. IR spectra indicated that all the fractions contain ethynyl group and alcohol groups. It appeared impracticable, however, not only to isolate but to identify the desired compound in the mixture. In route 2 , 4-bromomethyl-1,3-dioxane was prepared according to the literature ${ }^{12}$ in which the preparation of 4-chloromethyl-1,3-dioxane was described. The ethynylation of 4-bromomethyl-1,3-dioxane was unsuccessful. The starting material was recovered unreacted after the treatment with sodium acetylide or lithium acetylide in liquid ammonia. In route 3 , ethynylmagnesium bromide ${ }^{13}$ was reacted with allyl bromide in the presence of a catalytic amount of cuprous chloride to yield allylacetylene. This material was then subjected to the Prins reaction under reaction conditions accord- ing to the literature. ${ }^{14}$ The fractional distillation of the reaction mixture gave a distillate at a boiling range of $70-75^{\circ} \mathrm{C} / 2 \mathrm{mmHg}$. An IR spectrum, however, indicated that this product was not the desired compound, i.e., ether and carbonyl groups were observed but not the ethynyl group. Route 4 was a successful route for the preparation of TAH. The details are described in the experimental part of this report.

Figure 1 shows an IR spectrum of TAH. All the characteristic absorption bands are completely consistent with those of DAB. An NMR spectrum of TAH is shown in Figure 3 together with the assignments of the resonance peaks. In the last step of the TAH synthesis, two types of ketones were obtained as the result of side reactions. One of those was 1,3-diacetoxy-5hexanone(VI) which was isolated by fractional distillation of the reaction mixture. This compound could be obtained in a similar reaction to eq 4. Another ketone was 1-acetoxy-trans-3-

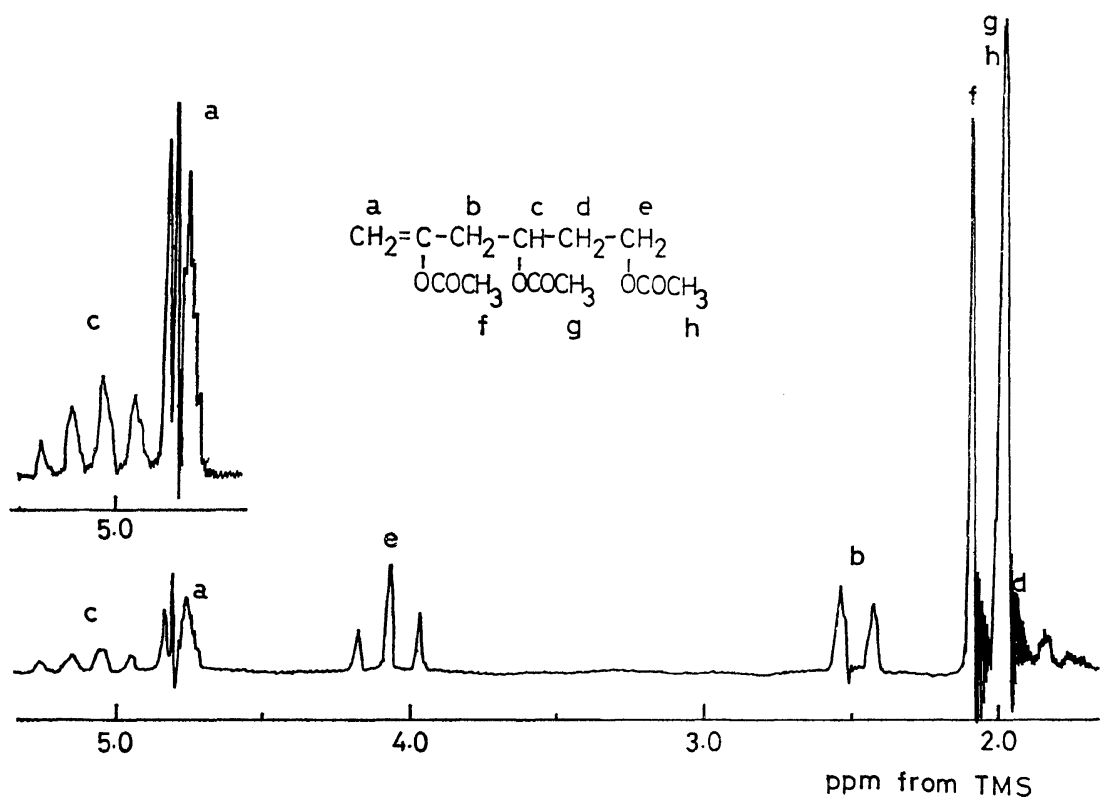

Figure 3. NMR spectra of 1,3,5-triacetoxy-5-hexene(TAH). 
Short Branching in Poly(vinyl alcohol). I.

hexene-5-one(VII), being isolated also by the fractional distillation. Compound VII is considered to be formed by the elimination of acetic acid from VI (eq 9). The methylene proton at the 4-position of VI might be active enough to cause the elimination.

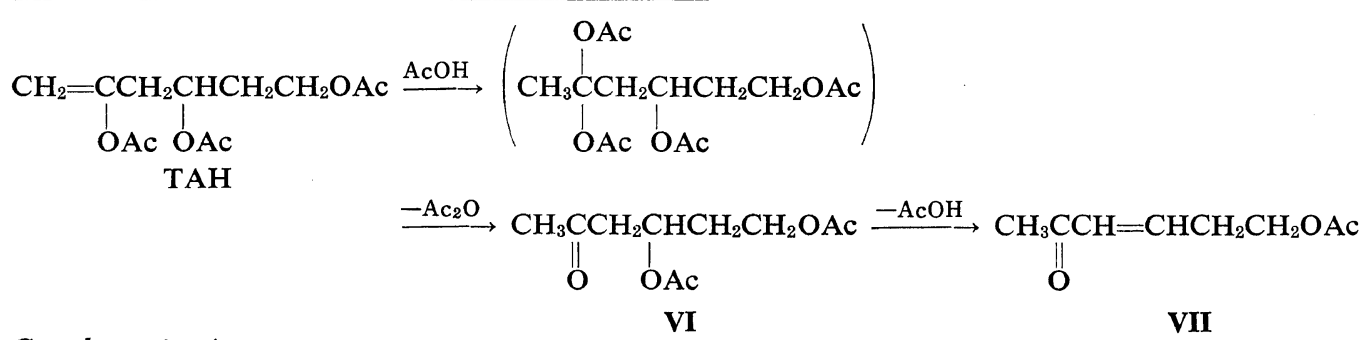

\section{Copolymerization}

The reaction conditions and results are summarized in Table $I$ for the bulk copolymerization of ${ }^{14} \mathrm{C}$-labelled $\mathrm{V}^{*} \mathrm{Ac}\left(\mathrm{M}_{1}\right)$ and $\operatorname{DAB}\left(\mathrm{M}_{2}\right)$. Copolymerization was carried out at $0^{\circ} \mathrm{C}$ to minimize the undesired formation of branches. The copolymer composition was determined by radioactivity measurements and Figure 4 shows the copolymer composition curve. The monomer reactivity ratios determined from a FinemanRoss plot by use of the least-squares method are $r_{1}=1.63 \pm 0.07$ and $r_{2}=0.52 \pm 0.13$. The rate of copolymerization was reduced with increasing $\mathrm{DAB}$ contents in comparison to the homopolymerization of vinyl acetate. The solubility of the copolymer was quite similar to that of poly(vinyl acetate).

In Table II are given the results of the copolymerization of $\mathrm{V}^{*} \mathrm{Ac}\left(\mathrm{M}_{1}\right)$ and $\mathrm{TAH}\left(\mathrm{M}_{2}\right)$ at $60^{\circ} \mathrm{C}$. This copolymerization was unsuccessful at $0^{\circ} \mathrm{C}$ because the rate of copolymerization was extremely low compared with that of the $\mathrm{V}^{*} \mathrm{Ac}-$

Table I. Bulk copolymerization of $\mathrm{V}^{*} \mathrm{Ac}\left(\mathrm{M}_{1}\right)$ and $\mathrm{DAB}\left(\mathrm{M}_{2}\right)$ at $0^{\circ} \mathrm{C}$ initiated by $(n-\mathrm{Bu})_{3} \mathrm{~B}-\mathrm{O}_{2}{ }^{\mathrm{a}}$

\begin{tabular}{ccccl}
\hline $\begin{array}{c}\mathrm{M}_{1}, \\
\mathrm{mmol}\end{array}$ & $\begin{array}{c}\mathrm{M}_{2}, \\
\mathrm{mmol}\end{array}$ & $\begin{array}{c}\text { Conversion, } \\
\%\end{array}$ & $\begin{array}{c}\text { Polymn } \\
\text { time, hr }\end{array}$ & $\begin{array}{c}\mathrm{M}_{1} \mathrm{~mol} \\
\text { fract in } \\
\text { copolymer }\end{array}$ \\
\hline 52.66 & 0 & 15.07 & 0.4 & 1.00 \\
50.72 & 7.46 & 18.46 & 3.5 & 0.920 \\
41.35 & 14.63 & 7.27 & 5.0 & 0.806 \\
36.42 & 22.87 & 5.30 & 6.5 & 0.748 \\
30.17 & 30.62 & 3.28 & 10 & 0.615 \\
8.57 & 14.04 & $2.95^{\mathrm{b}}$ & 28 & 0.530 \\
5.86 & 15.50 & $7.51^{\mathrm{b}}$ & 48 & 0.422 \\
3.76 & 19.66 & $4.43^{\mathrm{b}}$ & 48 & 0.285 \\
0 & 23.51 & $2.91^{\mathrm{b}}$ & 144 & 0
\end{tabular}

a $(n-\mathrm{Bu})_{3} \mathrm{~B}, 0.2 \mathrm{mmol}$; air, $0.5 \mathrm{ml}$.

b $(n-\mathrm{Bu})_{3} \mathrm{~B}, 0.5 \mathrm{mmol}$; air, $1.0 \mathrm{ml}$.

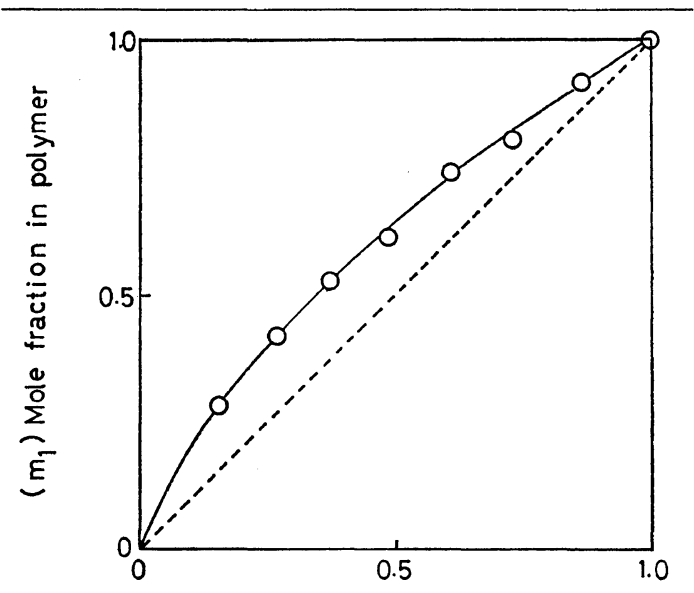

$\left(M_{1}\right)$. Mole fraction in monomer

Figure 4. Copolymer composition curve for $\mathrm{V}^{*} \mathrm{Ac}$ $\left(\mathrm{M}_{1}\right)$ and $\mathrm{DAB}\left(\mathrm{M}_{2}\right)$; initiated by $(n-\mathrm{Bu})_{3} \mathrm{~B}-\mathrm{O}_{2}$ at $0^{\circ} \mathrm{C}$.

Table II. Bulk copolymerization of $\mathrm{V}^{*} \mathrm{Ac}\left(\mathrm{M}_{1}\right)$ and $\mathrm{TAH}\left(\mathrm{M}_{2}\right)$ at $60^{\circ} \mathrm{C}$ initiated by $\mathrm{AIBN}^{\mathrm{a}}$

\begin{tabular}{rrrll}
\hline $\begin{array}{c}\mathrm{M}_{1}, \\
\text { mmol }\end{array}$ & $\begin{array}{c}\mathrm{M}_{2}, \\
\mathrm{mmol}\end{array}$ & $\begin{array}{c}\text { Conversion, } \\
\%\end{array}$ & $\begin{array}{c}\text { Polymn } \\
\text { time, hr }\end{array}$ & $\begin{array}{c}\mathrm{M}_{2} \text { mol } \\
\text { fract in } \\
\text { copolymer }\end{array}$ \\
\hline 20.76 & 0 & $17.2^{\mathrm{b}}$ & 0.25 & 1.00 \\
18.58 & 1.22 & 39.4 & 6.5 & 0.959 \\
18.49 & 2.38 & 70.6 & 25.5 & 0.902 \\
16.94 & 3.32 & 36.0 & 29 & 0.866 \\
16.51 & 4.38 & 40.4 & 35.5 & 0.852 \\
16.69 & 5.87 & 32.3 & 78 & 0.815 \\
14.77 & 6.41 & 23.0 & 73 & 0.761 \\
13.07 & 8.88 & 11.2 & 94.5 & 0.696 \\
11.91 & 8.86 & 33.0 & 113 & 0.682 \\
8.59 & 10.89 & 12.2 & 113 & 0.554 \\
\hline
\end{tabular}

[AIBN], $0.5 \mathrm{~mol} \%$.

b [AIBN], $0.25 \mathrm{~mol} \%$. 
DAB system even at low concentrations of TAH. The bulk homopolymerization of TAH at $60^{\circ} \mathrm{C}$ using $0.5 \mathrm{~mol} \%$ of AIBN did not give any detectable amount of polymer. It seems that TAH is lower in reactivity than $\mathrm{DAB}$ as shown in the rate of copolymerization mentioned above and also in the fact that DAB gave a low yield of homopolymer (Table I) even at $0^{\circ} \mathrm{C}$. Monomer reactivity ratios of TAH, as will be shown below, are essentially the same as those of DAB. Therefore, the low homopolymerizability of TAH might be due to the lower reactivity of the propagating TAH radical presumably because of steric hindrance. Figure 5 is a copolymer composition curve. Figure 5 shows that the monomer composition in the copolymer is close to that in the monomer feed. A Fineman-Ross plot can be applied even to high conversion data. The monomer reactivity ratios thus determined by use of the least-squares method are $r_{1}=1.49 \pm 0.03$ and $r_{2}=0.67 \pm 0.14$. All the copolymers are soluble in the same solvents as PVAc.

$P V A(I)$ and $P V A(I I)$

Figure 6 shows the IR spectra of $\operatorname{PVA}(\mathbf{I})$ and

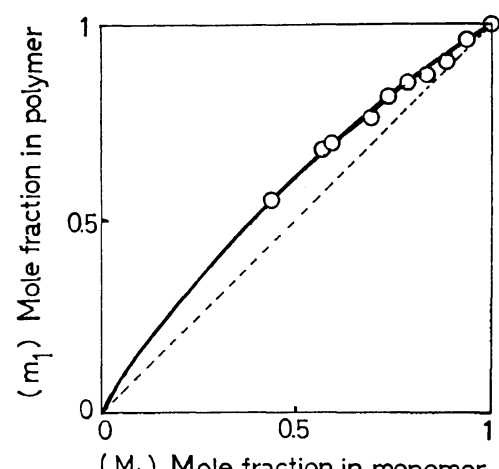

Figure 5. Copolymer composition curve for $\mathrm{V}^{*} \mathrm{Ac}$ $\left(\mathrm{M}_{1}\right)$ and TAH$\left(\mathrm{M}_{2}\right)$; initiated by AIBN at $60^{\circ} \mathrm{C}$.

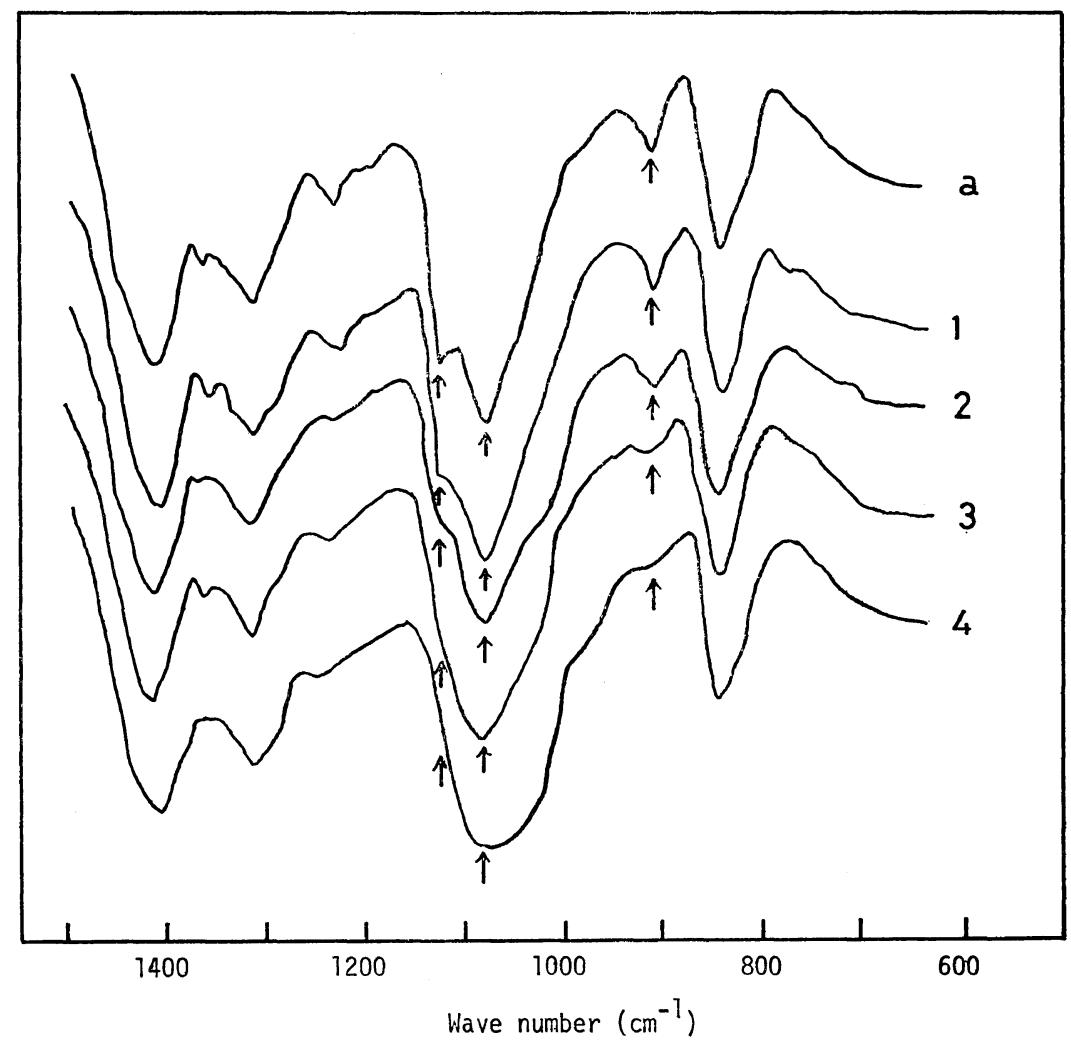

Figure 6. IR spectra of PVA derived from the copolymers of $V^{*} A c-D A B$ and $V^{*} A c-T A H:$ a, PVA; 1, PVA(I), DAB mol fract 0.055; 2, PVA(I), DAB mol fract 0.130; 3, PVA(II), TAH mol fract $0.065 ; 4$, PVA(II), TAH mol fract 0.129 . 
PVA(II), derived from the copolymers of $\mathrm{V}^{*} \mathrm{Ac}-$ $\mathrm{DAB}$ and $\mathrm{V}^{*} \mathrm{Ac}-\mathrm{TAH}$, respectively, together with that of PVA derived from PVAc. All the spectra were measured with films. It is clearly observed that the $1093-\mathrm{cm}^{-1}$ band, which is assigned to the $\mathrm{C}-\mathrm{O}$ stretching vibration of the secondary alcohol, becomes broader with increasing comonomer content. This is ascribable to the mixing of the $\mathrm{C}-\mathrm{O}$ stretching bands of the primary and tertiary alcohols which result from the incorporation of short branching units in PVA. The intensity of the $916-$ and $1141-\mathrm{cm}^{-1}$ band, which are very sensitive to crystallinity, ${ }^{15-18}$ showed a decrease as the comonomer content increased in both the cases of PVA(I) and PVA(II). This fact suggests that the incorporation of a minor amount of short branching units into PVA decreases its crystallinity and these facts are consistent with the melting point data. In Table III are listed the melting point of $\operatorname{PVA}(\mathbf{I})$

Table III. Melting point of $\operatorname{PVA}(\mathbf{I})$ and $\operatorname{PVA}(\mathbf{I I})$

\begin{tabular}{|c|c|c|c|}
\hline \multicolumn{2}{|c|}{$\operatorname{PVA}(\mathbf{I})^{\mathrm{a}}$} & \multicolumn{2}{|c|}{$\operatorname{PVA}(\mathbf{H})^{\mathrm{b}}$} \\
\hline $\begin{array}{c}\text { DAB } \\
\text { mol fract }\end{array}$ & $\underset{{ }^{\circ} \mathrm{C}}{\mathrm{mp}}$ & $\begin{array}{c}\text { TAH } \\
\text { mol fract }\end{array}$ & ${ }_{{ }^{\circ} \mathrm{C}}^{\mathrm{mp}}$ \\
\hline 0 & 232 & 0 & 232 \\
\hline 0.055 & 221 & 0.041 & 202 \\
\hline 0.075 & 219 & 0.065 & nil \\
\hline \multirow[t]{2}{*}{0.130} & nil & 0.085 & nil \\
\hline & & 0.129 & nil \\
\hline
\end{tabular}

a Polymerization condition of parent polymer; bulk, $(n-\mathrm{Bu})_{3} \mathrm{~B}-\mathrm{O}_{2}$, at $0^{\circ} \mathrm{C}$.

b Bulk, AIBN, at $60^{\circ} \mathrm{C}$.

and PVA(II) measured with DSC. It is obvious that the melting point falls remarkably with the incorporation of increasing short branching units. This tendency is more noticeable in the case of PVA(II), that is, the DSC peak due to the melting point was not observed when the mole fraction of short branching unit is more than 0.065 . Further study of the chemical structure and the characterization of $\operatorname{PVA}(\mathbf{I})$ and $\operatorname{PVA}(\mathbf{I I})$ will be described in a subsequent paper.

\section{EXPERIMENTAL}

\section{Synthesis of $D A B$}

1-Butyne-4-ol(I) was prepared according to a literature. ${ }^{7}$ From $45 \mathrm{~g}(2 \mathrm{~mol})$ of sodium metal in $500 \mathrm{ml}$ of liquid ammonia and $115 \mathrm{~g}(2.6 \mathrm{~mol})$ of ethylene oxide, $72.8 \mathrm{~g}(52 \%)$ of the product was obtained: bp $60^{\circ} \mathrm{C}(37 \mathrm{~mm})$.

4-Acetoxy-1-butyne(II) was obtained from the acetylation of $\mathrm{I}^{8} \mathrm{I}(92.8 \mathrm{~g})$ was acetylated with a mixture of acetic anhydride $(150 \mathrm{~m} l)$ and pyridine $(135 \mathrm{ml})$ at $100^{\circ} \mathrm{C}$ for $5 \mathrm{hr}$. The yield was $112.4 \mathrm{~g}(75.7 \%)$ : bp $50^{\circ} \mathrm{C}(16 \mathrm{~mm})$.

DAB was obtained by the addition of acetic acid to the ethynyl group of II. This reaction was carried out in accordance with the method used in the preparation of 2-acetoxy-1-hexene. ${ }^{9}$ A mixture of $3 \mathrm{~g}$ of red mercuric oxide, $2 \mathrm{ml}$ of $\mathrm{BF}_{3} \mathrm{OEt}_{2}$, and $2 \mathrm{ml}$ of absolute methanol was warmed at $30^{\circ} \mathrm{C}$ to partially dissolve the mercuric oxide. To this catalyst was added $35 \mathrm{~g}(0.85 \mathrm{~mol})$ of acetic acid with vigorous stirring, and then $80 \mathrm{~g}(0.72 \mathrm{~mol})$ of II was added dropwise through a dropping funnel. The addition of II required about $1 \mathrm{hr}$. Stirring was continued for another $2 \mathrm{hr}$ at room temperature. After stirring, the reaction mixture was poured into ice water, neutralized by adding $\mathrm{K}_{2} \mathrm{CO}_{3}$, and extracted with ether. The extract was dried over anhydrous $\mathrm{MgSO}_{4}$, the ether removed by distillation, and the residue distilled under reduced pressure. The yield of DAB was $28.5 \mathrm{~g}(28.8 \%)$ : bp $95^{\circ} \mathrm{C}(11 \mathrm{~mm})$.

Anal. Calcd for $\mathrm{C}_{8} \mathrm{H}_{12} \mathrm{O}_{4}: \mathrm{C}, 55.81 \% ; \mathrm{H}, 7.03 \%$ Found:

C, 55.92\%; H, 7.04\%

1-Acetoxy-3-butanone(III), formed as a byproduct, was isolated as a lower boiling fraction in the fractional distillation of the reaction mixture: IR 1720 (ketone $\nu \mathrm{C}=\mathrm{O}$ ), $1745 \mathrm{~cm}^{-1}$ (ester $\nu \mathrm{C}=\mathrm{C}) ; \operatorname{NMR} \delta 2.0(\mathrm{~s}, 3), 2.2(\mathrm{~s}, 3), 2.8(\mathrm{t}, 2), 4.3$ $\operatorname{ppm}(t, 2)$.

\section{Synthesis of $T A H$}

$\beta$-Acetoxypropionaldehyde(IV) was prepared according to Asao's method. ${ }^{10}$ From $110 \mathrm{~g}$ of acrolein and $240 \mathrm{~g}$ of acetic acid was obtained $34 \mathrm{~g}(15 \%)$ of IV: bp $56.5^{\circ} \mathrm{C}(6 \mathrm{~mm}) ; \mathrm{mp} 128-$ $130^{\circ} \mathrm{C}$ (2,4-dinitrophenylhydrazone).

1,3-Diacetoxy-5-hexyne(V) was prepared by the reaction of IV and propargyl bromide in the presence of zinc followed by acetylation with acetic anhydride. Prior to the reaction, the zinc dust was activated by treating with $2-\%$ hydrochloric acid for a few minutes, washed succes- 
sively with water, methanol and ether, and dried under reduced pressure. A solution of $130 \mathrm{~g}$ of propargyl bromide and $100 \mathrm{~g}$ of IV in $200 \mathrm{ml}$ of dried ether was added dropwise with stirring at room temperature to the mixture of $70 \mathrm{~g}$ of activated zinc and $130 \mathrm{~m} l$ of dried tetrahydrofuran. The addition required $4 \mathrm{hr}$. Stirring was continued for another $2 \mathrm{hr}$, the reaction temperature being kept between 15 and $25^{\circ} \mathrm{C}$. Acetic anhydride $(110 \mathrm{~g})$ was then added dropwise at the temperature below $30^{\circ} \mathrm{C}$ to the reaction mixture with stirring over a period of $2 \mathrm{hr}$. When the addition of acetic anhydride was complete, the reaction mixture was diluted with ether, washed several times with water, dried over anhydrous $\mathrm{MgSO}_{4}$, then distilled under reduced pressure, giving $122 \mathrm{~g}(72 \%)$ of $\mathrm{V}$ : bp $103-107^{\circ} \mathrm{C}(0.25$ $\mathrm{mm}) ; n_{\mathrm{D}}^{25} 1.444 ; d_{4}^{25} 1.066 ;$ IR 3280 (ester $\nu \mathrm{C}-\mathrm{H}$ ), 2970, 2130 (ethynyl $\nu \mathrm{C} \equiv \mathrm{C}$ ), $\quad 1742 \mathrm{~cm}^{-1}$ (ester $\nu \mathrm{C}=\mathrm{O})$; $\mathrm{NMR} \delta, 2.17\left(\mathrm{~d}, 1, \mathrm{CH}^{\mathrm{a}}\right), 2.49\left(\mathrm{q}, 2, \mathrm{CH}_{2}^{\mathrm{b}}\right)$, 4.98(m, 1, $\left.\underline{\mathrm{CH}}^{\mathrm{c}}\right), 2.00\left(\mathrm{q}, 2, \mathrm{CH}_{2}{ }^{\mathrm{d}}\right), 4.12\left(\mathrm{t}, 2, \mathrm{CH}_{2}{ }^{\mathrm{e}}\right)$, and 1.99, $2.02 \mathrm{ppm}\left(\mathrm{s}, 6, \mathrm{C}_{3}{ }^{\mathrm{f}}, \mathrm{C}_{3}{ }^{\mathrm{g}}\right)$.

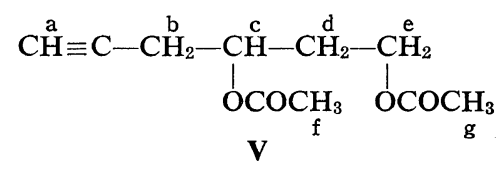

Anal. Calcd for $\mathrm{C}_{10} \mathrm{H}_{12} \mathrm{O}_{4}$ : C, $60.59 \% ; \mathrm{H}, 7.12 \%$. Found: $\quad \mathrm{C}, 60.45 \% ; \mathrm{H}, 7.00 \%$.

TAH was prepared by the addition reaction of acetic acid to the ethynyl group of $\mathbf{V}$ in accordance with the method of Hennion and Nieuwland. ${ }^{9}$ The mixture of $3 \mathrm{~g}$ of red mercuric oxide, $2 \mathrm{ml}$ of $\mathrm{BF}_{3} \mathrm{OEt}_{2}$, and $3 \mathrm{~g}$ of absolute methanol was warmed at $40^{\circ} \mathrm{C}$ to partially dissolve the mercuric oxide. To this catalyst was added $35 \mathrm{~g}$ of acetic acid with stirring over a period of $50 \mathrm{~min}$. After addition of the acetic acid, $19 \mathrm{ml}$ of this reaction mixture was added to $50 \mathrm{~g}$ of $\mathrm{V}$ at the rate of $0.5 \mathrm{ml} / \mathrm{min}$ to maintain the reaction temperature at $55^{\circ} \mathrm{C}$. The reaction mixture was stirred at the same temperature for another $3 \mathrm{hr}$ after the addition was complete, then poured into water and extracted with chloroform. 1,3-Diacetoxy-5-hexanone(VI) was produced as a by-product whose boiling point is very close to that of TAH. Treatment with aqueous $\mathrm{NaHSO}_{3}$ was found to be the best method for the removal of VI. The chloroform extract was dissolved into ether after the chloro- form was evaporated. The ethereal solution was shaken successively with an aqueous 15- $\%$ $\mathrm{NaHSO}_{3}$ solution and water, dried over $\mathrm{MgSO}_{4}$, and then distilled. After simple distillation under reduced pressure, the distillate was subjected to rectification through a fractionating column packed with a $40-\mathrm{cm}$ length of glass helices. The yield of TAH was $9.1 \mathrm{~g}(18.1 \%)$ : bp $87^{\circ} \mathrm{C}$ $(0.1 \mathrm{~mm}) ; n_{\mathrm{D}}^{25} 1.4453 ; d_{4}^{25} 1.1081$.

Anal. Calcd for $\mathrm{C}_{12} \mathrm{H}_{18} \mathrm{O}_{6}$ : C, 55.81\%; H, 7.03\% Found: $\quad \mathrm{C}, 55.90 \% ; \mathrm{H}, 7.04 \%$

When the reaction mixture was not treated with aqueous $\mathrm{NaHSO}_{3}, \mathrm{VI}$ was isolated as a slightly lower boiling distillate than TAH by the repeated fractional distillation of the reaction mixtures: bp $93^{\circ} \mathrm{C}(0.3 \mathrm{~mm})$; IR 1745 (ester $\nu \mathrm{C}=\mathrm{O}$ ), 1725 (ketone $\nu \mathrm{C}=\mathrm{O}$ ), and 1430,1375 $\mathrm{cm}^{-1}$ (methyl $\delta_{\mathrm{s}} \mathrm{C}-\mathrm{H}$ ); NMR $\delta$ 2.12(s, 3, $\mathrm{CH}_{3}{ }^{\mathrm{a}}$ ), $2.70\left(\mathrm{~d}, 2, \mathrm{CH}_{2}^{\mathrm{b}}\right), 5.23\left(\mathrm{~m}, 1, \underline{\mathrm{H}}^{\mathrm{c}}\right), 1.88\left(\mathrm{q}, 2, \mathrm{CH}_{2}^{\mathrm{d}}\right)$, $4.08\left(\mathrm{t}, 2, \mathrm{C}_{\mathrm{H}^{2}} \mathrm{e}\right)$, and $1.96,1.98 \mathrm{ppm}\left(\mathrm{s}, 6, \overline{\mathrm{CH}}_{3}{ }^{\mathrm{f}}\right.$, $\left.\mathrm{C}_{3} \mathrm{~g}\right)$.

Anal. Calcd for $\mathrm{C}_{10} \mathrm{H}_{16} \mathrm{O}_{5}$ : C, 55.54\%; H, 7.46\% Found: C, $55.26 \% ; \mathrm{H}, 7.53 \%$<smiles>COCCC(CC(C)=O)OC(C)=O</smiles>

1-Acetoxy-trans-3-hexene-5-one(VII) was also isolated as a lower boiling distillate: bp 62$70^{\circ} \mathrm{C}(0.3 \mathrm{~mm})$; IR 1735 (ester $\left.\nu \mathrm{C}=\mathrm{O}\right), 1675$ (vinylene $\nu C=C$ ), 1630 (ketone $\nu C=0), 1375,1430$ (methyl $\delta_{\mathrm{s}} \mathrm{C}-\mathrm{H}$ ), and $965 \mathrm{~cm}^{-1}$ (trans-vinylene $\delta \mathrm{C}-\mathrm{H}) ; \mathrm{NMR} \delta$ 1.8(s, 3, $\left.\mathrm{CH}_{3}^{\mathrm{a}}\right), 5.9\left(\mathrm{~d}, 1, \mathrm{CH}^{\mathrm{b}}\right)$, 6.6(m, $\left.1, \mathrm{CH}^{\mathrm{c}}\right), \quad 2.4\left(\mathrm{q}, 2, \mathrm{C}_{2}{ }^{\mathrm{d}}\right), \quad 4.0\left(\mathrm{t}, 2, \mathrm{CH}_{2}{ }^{\mathrm{e}}\right)$, and $2.0 \mathrm{ppm}\left(\mathrm{s}, 3, \mathrm{CH}_{3}{ }^{\mathrm{f}}\right)$.<smiles>CC(=O)/C=C/CCOC(C)=O</smiles>

\section{Copolymerization}

Radioactive vinyl-1,2- ${ }^{14} \mathrm{C}$ acetate $\left(\mathrm{V}^{*} \mathrm{Ac}\right)$ was used as a comonomer for the sake of accurate determination of the copolymer composition. The $\mathrm{V}^{*}$ Ac obtained from England Nuclear Corp. was washed several times with an aqueous $5-\%$ $\mathrm{NaHSO}_{3}$ solution, washed with water, dried with $\mathrm{CaCl}_{2}$, and then distilled through a Widmer 
column three times; bp $72.5^{\circ} \mathrm{C}$. The specific radioactivity of $\mathrm{V}^{*} \mathrm{Ac}$ used for this experiment was $0.05 \mu \mathrm{Ci} / \mathrm{g}$. Copolymerization of $\mathrm{V}^{*} \mathrm{Ac}$ and $\mathrm{DAB}$ was carried out at $0^{\circ} \mathrm{C}$ in the presence of $(n-\mathrm{Bu})_{3} \mathrm{~B}-\mathrm{O}_{2}$ as an initiating system using a Schlenk tube. After the polymerization, the contents of the tube were poured into a large excess of $n$-hexane to precipitate the polymer. The separated polymer was purified by reprecipitation into $n$-hexane from an acetone solution, dried, dissolved in benzene, and recovered by a freeze-drying technique.

Copolymerization of $\mathrm{V}^{*} \mathrm{Ac}$ and $\mathrm{TAH}$ was performed as follows. An ampoule containing known amounts of $\mathrm{V}^{*} \mathrm{Ac}, \mathrm{TAH}$ and $2,2^{\prime}$-azobisisobutyronitrile was degassed several times in a vacuum system $\left(<10^{-3} \mathrm{mmHg}\right)$ and sealed. Polymerizations were carried out in a thermostat at $60^{\circ} \mathrm{C}$. After the required time of polymerization, the ampoule was opened, and the contents diluted with acetone and poured into a large excess of a mixture of ether and petroleum ether $(1: 1, \mathrm{v} / \mathrm{v})$ with stirring to precipitate the polymer. The separated polymer was purified three times by reprecipitation into the mixture of ether and petroleum ether from an acetone solution, dried, dissolved in benzene, and recovered by a freezedrying technique.

\section{Hydrolysis of Copolymer}

Ten grams of copolymer were dissolved in a mixture of $200 \mathrm{ml}$ of acetone and $500 \mathrm{ml}$ of methanol, then $10 \mathrm{ml}$ of an aqueous $25-\% \mathrm{NaOH}$ solution was added. The reaction mixture was held at room temperature overnight until the precipitation of PVA was completed. The PVA was separated, washed by methanol, dissolved into water, and recovered by a freeze-drying technique.

\section{Measurements}

IR spectra were measured on a HITACHI EPI-2 spectrometer. NMR spectra were measured in a $10-\% \mathrm{CCl}_{4}$ solution using a VARIAN A-60 spectrometer. The radioactivity of the copolymer was measured by using a PACKARD MODEL 3002 scintillation spectrometer. For the prepa- ration of the sample solution for the radioactive counting, about $0.1 \mathrm{~g}$ of copolymer was dissolved into $10 \mathrm{~m} l$ of toluene containing scintillators $(5 \mathrm{~g}$ of PPO and $0.3 \mathrm{~g}$ of dimethyl POPOP per liter toluene). The melting point of the $\operatorname{PVA}(\mathbf{I})$ and PVA(II) was measured with a RIGAKU DENKI YDS-TYPE differencial scanning calorimeter, using $8 \mathrm{mg}$ of samples at the program rate of $20^{\circ} \mathrm{C} / \mathrm{min}$.

\section{REFERENCES}

1. S. Nozakura, Y. Morishima, and S. Murahashi, J. Polym. Sci., Part A-1, 10, 2781 (1972).

2. S. Nozakura, Y. Morishima, and S. Murahashi, ibid., 10, 2853 (1972).

3. I. Sakurada, Y. Sakaguchi, and Z. Shiiki, Kobunshi Kagaku (Chem. High Polymers), 21, 289 (1964).

4. K. Kikukawa, S. Nozakura, and S. Murahashi, Polymer. J., 3, 52 (1972).

5. M. J. Roedel, J. Amer. Chem. Soc., 75, 6110 (1953).

6. A. H. Willbourn, J. Polym. Sci., 34, 569 (1959).

7. K.W. Greenlee and A. L. Henne, "Inorganic Synthesis," Vol. 2, p 75.

8. C. C. J. Culrenon and T. A. Geissman, J. Amer. Chem. Soc., 83, 1647 (1961).

9. G. F. Hennion and J. A. Nieuwland, ibid., 56, 1802 (1934).

10. M. Asao, Kogyo Kagaku Zasshi (J. Chem. Soc. Japan, Ind. Chem. Sect.), 70, 1501 (1967).

11. H. J. Prins, Chem. Weekbl., 16, 1072 (1919); Chem. Abstr., 13, 3155 (1919).

12. C. C. Price and I. V. Krishnamurti, J. Amer. Chem. Soc., 72, 5335 (1950).

13. E. R. H. Jones, L. S. Kattebol, and M. C. Whiting, J. Chem. Soc., 4765 (1956).

14. S. G. Matsoyan and A. A. Saakyan, Zh. Obshch. Khim., 33, 3795 (1963).

15. E. Nagai and N. Sagane, Kobunshi Kagaku (Chem. High Polymers), 12, 195 (1955).

16. H. Tadokoro, S. Seki, and I. Nitta, Bull. Chem. Soc. Japan, 28, 559 (1955).

17. H. Tadokoro, S. Seki, I. Nitta, and R. Yamadera, J. Polym. Sci., 28, 244 (1958).

18. K. Fujii and J. Ukida, Makromol. Chem., 65, 74 (1963). 